\title{
A (DES)CONFIANÇA DO CIDADÃO NO PODER LEGISLATIVO E A QUALIDADE DA DEMOCRACIA NO BRASIL
}

\section{Cristina Jacobson Jácomo Cinnanti*}

\begin{abstract}
Resumo: O estudo apresenta reflexões sobre a democracia brasileira, abordando a representação, o impacto da imagem do Poder Legislativo sobre a participação popular e os efeitos dessas relações sobre a qualidade do regime democrático vivenciado. Enfoca-se a correlação entre a confiança da população no poder constituído, o pleno exercício da cidadania e o fortalecimento da democracia, enfatizando o papel da educação cidadã nesse processo.
\end{abstract}

Palavras-chave: democracia; representatividade; cidadania; Poder Legislativo; sociedade civil organizada.

Abstract: The essay presents reflections on Brazilian democracy, addressing the representation, the impact of the image of the Legislative on popular participation and the effects of these relationships on the quality of democratic regime experienced. It focuses on the correlation between public confidence in the authorities, the full exercise of citizenship and the strengthening of democracy, emphasizing the role of citizen education in this process.

Keywords: democracy; representation; citizenship; Legislative; organized civil society.

\section{Reflexões sobre a democracia brasileira}

Após décadas de dominação ditatorial em boa parte do mundo, o século XX viu o estabelecimento de regimes democráticos na maioria das nações, consolidando-se a democracia, inicialmente, nos países desenvolvidos e, em seguida, em alguns dos países em desenvolvimento. No princípio, predominou a democracia liberal, considerada a democracia das elites; posteriormente vigorou a social-democracia, norteada pela opinião pública; atualmente a

*Mestre em Psicologia pela Universidade de Brasília e Analista Legislativo da Câmara Legislativa do Distrito Federal (cristinacinnanti@gmail.com) 
tendência é a democracia participativa, na qual cresce a atuação de organizações da sociedade civil em favor da responsabilização social (Bresser-Pereira, 2005).

Ao abordar a dimensão sociológica da democracia, Chauí (2001) contrapõe o modelo formulado por Schumpeter, baseado na apatia política do cidadão, reforçada pelas desigualdades sociais e econômicas, à democracia participativa idealizada por McPherson, que pressupõe o aumento da participação da sociedade civil no espaço político e enfatiza a importância dos movimentos sociais (Chauí, 2001).

Como síntese da confrontação desses dois modelos, Chauí (2001) descreve as condições sociais da democracia, segundo um conjunto de critérios políticos e sociais:

1) A legitimidade do poder é assegurada pelo fato de os dirigentes serem obtidos pela consulta popular periódica, onde a ênfase recai sobre vontade majoritária. As condições aqui postuladas são, pois, a cidadania e a eleição.

2) A eleição pressupõe a competição entre posições diversas, sejam elas de homens, grupos ou partidos. A condição aqui postulada é a existência de associações, cuja forma privilegiada é o partido.

3) A competição pressupõe a publicidade das opiniões e liberdade de expressão. A condição aqui postulada é a existência da opinião pública como fator de criação da vontade geral.

4) A repetição da consulta em intervalos regulares visa proteger a minoria garantindo a sua participação em assembleias onde se decidem as questões de interesse público, e visa proteger a maioria contra o risco de perpetuação de um grupo no poder. As condições aqui postuladas são a existência de divisões sociais (maioria/minoria) e parlamentos.

5) A potência política é limitada pelo judiciário, que, não só garante a integridade do cidadão face aos governantes, como ainda garante a integridade do sistema contra a tirania, submetendo o próprio poder à lei, isto é, à Constituição. As condições aqui postuladas são a existência do direito público e privado, a lei como defesa contra a tirania e, por conseguinte, a defesa da liberdade dos cidadãos.

(Chauí, 2001, p. 141)

Benevides (2002) destaca que, na Constituição de 1988, são contempladas as formas de democracia direta e representativa, pois está no art. $1^{\circ}$ que "o poder emana do povo" e que este povo exercerá o poder "por meio de representantes eleitos ou diretamente".

O descrédito da população brasileira na classe política é um elemento histórico, que tem se perpetuado e, até mesmo, aumentado ao longo do tempo. Como bem pontua Benevides (2002), a maior falha na representação política no Brasil decorre da falta de responsabilidade e de responsabilização do mandatário perante o povo, legítimo titular do poder. Esse é um dos fatores determinantes desse descrédito epidêmico.

Benevides (2002) propõe um tipo complementar de democracia - a democracia semidireta - baseada em um modelo que contemple a utilização de mecanismos da democracia direta para corrigir desvios na representação política tradicional. Nesse sentido, ela enfatiza a função complementar do plebiscito, do referendo e da iniciativa popular, que podem ser utilizados para confirmar ou não as decisões tomadas pela classe política. 
Temos a Constituição de 1988 como a mais democrática das Cartas Magnas brasileiras. Sem dúvida, ela enfocou os direitos civis e a participação popular. No entanto, Carvalho (2008) chama a atenção para o fato de que a cidadania defendida pela Constituição Cidadã permeia várias dimensões, como educação, saúde e segurança, porém o exercício de alguns dos direitos previstos constitucionalmente não implica o exercício dos demais. Para ele, não há, na realidade, o pleno gozo da cidadania ou dos direitos civis: "Uma cidadania plena, que combine liberdade, participação e igualdade para todos, é um ideal desenvolvido no Ocidente e talvez inatingível" (Carvalho, 2008, p. 9). Nessa linha de pensamento, o pleno exercício da cidadania estaria respaldado pelo gozo dos direitos civis, políticos e sociais.

Vieira (2001) discorre sobre a conceituação de cidadania e destaca, como um dos elementos dessa definição, a distinção entre direitos e deveres ativos e passivos. Nessa ótica, afirma que "a cidadania é constituída tanto por direitos passivos de existência, legalmente limitados, como por direitos ativos que propiciem a capacidade presente e futura de influenciar o poder político" (Vieira, 2001, p. 35).

O exercício da cidadania não é prerrogativa individual. Ele vai depender da convergência entre a postura e consciência do cidadão e a atuação do Estado, suas normas, capacidade de garantir os direitos da população e de possibilitar a participação popular nas suas decisões. A forma de organização e funcionamento da Administração Pública, por sua vez, decorrerá dos preceitos da democracia e da cidadania em vigor em determinada sociedade.

A Administração Pública Brasileira passou por diversos momentos e está agora procurando consolidar em suas instituições o modelo gerencial adaptado da Inglaterra, inspirado nas práticas das empresas privadas. Esse modelo gerencial, chamado Nova Gestão Pública ou Administração Pública Gerencial, tem o propósito de oferecer maior autonomia e responsabilidade aos administradores públicos e de tornar as agências executoras dos serviços sociais mais descentralizadas (Bresser-Pereira, 2010). Infelizmente, constata-se que, no Brasil, as práticas da Nova Gestão Pública têm convivido com formas burocráticas e patrimonialistas ainda muito arraigadas na cultura nacional.

Apesar disso, não se pode desprezar a importância da adoção desse novo modelo, que migra do foco nos interesses do Estado - visão dominante na administração burocrática - para o foco no cidadão, visando a oferecer um serviço público de melhor qualidade (Coutinho, 2000).

Tratando-se de gestão pública, a gestão do Poder Legislativo apresenta desafios bastante peculiares. Embora não seja uma exclusividade desse Poder, nesse contexto ainda são comuns as práticas patrimonialistas. A gestão do Legislativo difere em alguns aspectos da gestão do Executivo e do Judiciário, por serem esses dois ambientes mais técnicos, ou seja, ambientes em que as questões políticas, apesar de presentes, interferem em menor intensidade. O Poder Legislativo é mais flexível, mais aberto, mais permeável, e profundamente afetado pelos elementos da política. 
Um dos grandes desafios da gestão do Legislativo, senão o maior deles, é admitir a dimensão política como legítima, aceitando-a como elemento estrutural do contexto legislativo, e desenvolver práticas gerenciais que absorvam esse elemento, sem antagonizar as esferas política e administrativa.

No entanto, é importante frisar que, embora o mais democrático dos poderes, o Legislativo não pode prescindir de reger-se pelos dispositivos e princípios constitucionais, os quais devem guiar as ações da administração e de todos os gestores dos órgãos desse Poder.

Os princípios constitucionais da Administração Pública - legalidade, impessoalidade, moralidade, publicidade e eficiência - são normas gerais que fundamentam, orientam e auxiliam a interpretação da fonte subsidiária. Os princípios são considerados valores, o núcleo do sistema jurídico, e, como tal, devem fundamentar a ação do legislador ou do administrador público.

Podemos considerar que a conformidade da ação governamental aos princípios referenciados é a base da construção da confiança do cidadão - por extensão, da população nas instituições públicas e, por consequência, no próprio instituto da democracia. A existência dessa confiança é um chamamento ao exercício da cidadania, aí compreendida como a participação do povo mediante o gozo de direitos e o cumprimento de deveres em relação à coletividade e ao próprio Estado.

Incluem-se no exercício da cidadania a fiscalização da atuação da Administração Pública e a cobrança por um serviço público de qualidade. Estendemos a noção de serviço público de qualidade, neste momento, também à produção de leis de qualidade, que promovam o bem coletivo e que sejam originadas em conformidade com os ritos do processo legislativo e com os preceitos constitucionais.

A população espera de seus legisladores ética e comprometimento com a Nação. Não basta viver em um país democrático, laureado com a conquista da liberdade de expressão, enquanto, lamentavelmente, a impunidade e o individualismo continuarem a dirigir as ações de muitos mandatários do poder, constituindo-se em uma ameaça ao exercício da cidadania e à credibilidade do povo nas instituições públicas.

O descrédito verificado em relação ao Parlamento contamina o próprio corpo profissional do Legislativo, indivíduos que, no papel de cidadãos, deploram a instituição em que trabalham e, no papel de servidores, envergonham-se por integrar os quadros de ente tão depreciado pela população. Constata-se, muitas vezes, uma dissociação: o próprio servidor não se percebe como parte da Instituição e, como tal, detentor de mecanismos e instrumentos que contribuam para que os atos administrativos estejam consoantes aos princípios constitucionais.

Se os gestores do Legislativo - em primeiro lugar, as autoridades políticas que dirigem a Instituição e, subsidiariamente, os servidores responsáveis por gerir as diversas unidades administrativas - nortearem suas ações e decisões pelos princípios da legalidade, da impessoalidade, da moralidade, da publicidade e da eficiência, em muito contribuirão para 
aumentar a confiança de todo o país no Parlamento. Um Poder Legislativo que atue em favor do bem comum, que seja ético e transparente promoverá o fortalecimento da democracia, ao ser considerado pelo real titular do poder - o povo - legítimo em sua representação. Da mesma forma, incentivará a participação popular nas suas diversas formas, o que representará um incremento no exercício da cidadania. Assim, podemos considerar que, da confiança da população no poder constituído e da qualidade do serviço público oferecido, decorre o pleno exercício da cidadania e o fortalecimento da democracia.

\section{$2 \mathrm{O}$ fortalecimento da democracia}

O Poder Legislativo tem sua atuação baseada na delegação. O povo, titular do poder, delega-o ao político, que o exerce por meio da representação. Ao agir em nome dos que o elegeram, o parlamento representa o País. Além disso, pode-se considerar que o parlamento espelha a Nação, ou seja, possui as características e reflete os interesses dos vários segmentos da sociedade (Ames, 2010).

Espera-se que o mandatário volte sua atuação para atender aos interesses e necessidades do povo, expressando a vontade popular nas decisões governamentais. No entanto, no Brasil, os eleitores pouco influenciam o desempenho do mandato, pois, uma vez em exercício, o parlamentar decide por si próprio, e não há mecanismos de controle de suas ações por parte do eleitor (Ames, 2010). A democracia representativa enfrenta o paradoxo de que o povo não participa do processo de tomada de decisão (Moisés, 2008).

Essa prática instituída gera dissonância entre os anseios da população e os encaminhamentos dados pelo Poder Legislativo. A incongruência se estende à expectativa que o cidadão tem sobre a atuação do parlamento no que concerne à ética, valores e moral e o que ocorre efetivamente.

O parlamento brasileiro, nas diversas esferas e unidades federativas, tem protagonizado escândalos amplamente repercutidos na mídia, nos quais parlamentares encontram-se envolvidos em corrupção. A recorrência desses eventos levou o Poder Legislativo ao descrédito generalizado, refletindo-se na construção de imagem negativa perante a opinião pública. A baixa avaliação ocorre também dentro das instituições legislativas, cujos servidores ora incorporam uma autoimagem negativa, ora dissociam-se da organização, como se dela não fizessem parte, evitando uma identificação pessoal com as práticas que reprovam, conforme demonstram pesquisas de valores e de clima organizacional realizadas no âmbito do Legislativo.

O Poder Legislativo é, via de regra, alvo de superexposição na mídia, tendo seus aspectos falhos enfatizados pelos meios de comunicação. Isso contribui para impregnar o imaginário popular com o conteúdo divulgado e força o processo de construção de uma avaliação negativa do parlamento. Nessa avaliação, tende-se a generalizar os pontos fracos, que 
raramente são confrontados pela divulgação das ações relevantes do Legislativo. Há uma omissão da instituição no que tange a levar ao conhecimento da população a importância e os feitos desse Poder.

Campos (2009) discorre sobre a relação entre a opinião pública e as políticas públicas em sociedades democráticas, ressaltando o caráter de complexidade que decorre dos múltiplos atores e interesses envolvidos. Para ele, existe uma relação dialética entre a opinião pública e as políticas públicas, que se afetam mutuamente. Esse autor considera que a opinião pública resulta, em grande parte, da influência dos meios de comunicação sobre os julgamentos e atitudes dos indivíduos. No entanto, as próprias ações do Governo também influenciam a formação de juízo de valor na população.

Opondo-se a essas reflexões, Howlett (2002) avalia que há pouca ligação entre a opinião pública e os resultados políticos observados. Segundo ele, a descoberta de que a opinião pública não afeta significativamente a elaboração de políticas públicas gera o que se chama de frustração democrática. No entanto, a análise do papel da opinião pública nas democracias não deve ser simplista, ao contrário, requer a observação dos processos de governança e da elaboração de políticas (Howlett, 2002).

O juízo que a população faz a respeito das instituições governamentais apresenta reflexos sobre a intensidade e a qualidade da participação popular em dado momento, repercutindo na qualidade da democracia vivenciada. De um lado, a avaliação negativa pode desmotivar a participação dos cidadãos, por acreditarem que sua atuação é vã. De outro lado, pode mobilizá-los a lutar por uma ruptura com o status, em uma tentativa de modificar a ordem vigente, a exemplo do que ocorreu este ano no Brasil, com a manifestação popular em torno da elaboração e aprovação da "Lei da Ficha Limpa".

Moisés (2008) alerta que, no Brasil, há déficits institucionais relativos à legalidade e à responsabilização do governo, os quais comprometem a qualidade da democracia, pois são obstáculos para satisfazer a expectativa do cidadão quanto ao sistema político:

Quanto à qualidade da democracia, a situação brasileira aponta para existência de déficits institucionais que afetam princípios básicos como, por exemplo, o primado da lei ou a responsabilização de governos, comprometendo a capacidade do sistema político de responder às expectativas dos cidadãos. A insatisfação com a democracia e a desconfiança de suas instituições indicam que eles não sentem que seus direitos de participação e representação - de que dependem a igualdade política e seus corolários, como a igualdade social e econômica - sejam canais efetivos para enfrentar problemas como a corrupção ou as dificuldades econômicas. Nesse contexto, a análise dos dados aponta para a existência de conexão entre a ambivalência a respeito de valores políticos, a insatisfação com a democracia e a desconfiança de instituições, como partidos e Congresso Nacional. Não deveria surpreender, nessa situação, que o país seja um campeão de baixos índices de identificação partidária, de avaliação negativa do Congresso Nacional e de incapacidade dos eleitores de lembrar-se dos políticos em quem votaram nas últimas eleições. A experiência de práticas de corrupção envolvendo governos, partidos políticos e membros do Congresso Nacional, 
sem que os meios institucionais de controle sejam considerados efetivos, ajuda a explicar a escolha que tantos cidadãos fazem de modelos de democracia "sem partidos" e "sem Congresso Nacional". Resta saber se esse processo de progressiva deslegitimação das instituições básicas da democracia representativa poderá ser usado, a médio ou longo prazos, para alimentar alternativas antidemocráticas (Moisés, 2008).

A Câmara dos Deputados tem sido palco de inúmeros episódios de corrupção e de malversação dos recursos públicos. Obviamente, a imprensa os repercute incansavelmente, contribuindo para construir e sedimentar opinião pública desfavorável a essa casa legislativa. Escândalos como "o mensalão do PT", referente a esquema de compra de votos de parlamentares, deflagrado em 2005; "o gasto de verbas públicas para o financiamento de campanhas eleitorais" verificado em 2008; "a farra das passagens no Congresso Nacional", no qual parlamentares em exercício e licenciados utilizavam indevidamente verbas da Câmara dos Deputados e do Senado Federal para a compra de passagens para si mesmos e para parentes e amigos, denunciado em 2009, além de renúncias de parlamentares para evitar a possibilidade de perda de mandato e a impunidade reinante são exemplos de situações que comprometem a credibilidade da Câmara dos Deputados e geram impacto sobre os alicerces da democracia representativa.

Pesquisa realizada pela Datafolha, em março de 2010, demonstra elevado índice de reprovação do Legislativo Federal. O desempenho dos deputados federais e dos senadores foi, de forma geral, avaliado como ruim e péssimo por $33 \%$ dos respondentes; regular, por $41 \%$ e ótimo e bom, por apenas $16 \%$ dos questionados.

A insatisfação explícita da população com o quadro político atual levou os eleitores a se posicionarem nas urnas, resultando em grande renovação do Congresso Nacional. Segundo o DIAP, houve renovação de 66,66\% das 54 vagas em disputa para o Senado Federal, com a eleição de 35 senadores novatos. Em relação às 81 cadeiras da Casa, a renovação foi de 44,44\%. O Portal da Câmara dos Deputados informa a renovação de 46,4\% do colegiado, com a eleição de 238 deputados novatos.

As eleições periódicas no regime democrático servem como mecanismo de controle, dando a oportunidade de o eleitor rever sua delegação e buscar eleger um corpo parlamentar que o represente com maior qualidade e precisão.

Atualmente, os parlamentares são eleitos pela sociedade civil organizada, que deseja um representante para ter poder de negociação junto ao Governo. A atuação política segmentada, dirigida à base eleitoral, relegando à menor importância parcelas expressivas da sociedade, leva à não-legitimação dos políticos pelo povo. Vê-se aí comprometido o lastro do mandatário do poder na democracia brasileira - a representação -, uma vez que o cidadão não se reconhece naquele que o representa. 
A avaliação do Poder Legislativo - seja ela do Congresso Nacional ou dos Legislativos estaduais e municipais - causa impacto sobre o comportamento da população, que pode ser expresso pela omissão e desligamento ou pelo incremento da sua participação e da fiscalização e controle das ações do parlamentar.

A democracia brasileira sofreu alguns períodos de interrupção, substituída por regimes autoritários. O regime democrático atual é fenômeno relativamente recente, se pensarmos em termos históricos. Data da década de 1980, com as primeiras eleições diretas em 1989, após 29 anos de autoritarismo. Vivemos uma democracia ainda imatura, na qual ambas as partes estão aprendendo a desempenhar seus papéis: os políticos, mandatários do poder, exercitam suas funções, testando os limites do que pode ser aceitável pela população; o povo, titular do poder, aprende a avaliar seus representantes e a referendá-los ou não. Aprende também a participar, a cobrar, a fiscalizar.

Serão necessárias algumas legislaturas a mais para que o eleitor e os parlamentares estejam suficientemente amadurecidos de forma a construir um Legislativo mais respeitado e que represente com dignidade o povo brasileiro.

\section{A função representativa do Legislativo e a educação cidadã.}

Em nossa democracia representativa, ao Poder Legislativo atribuem-se as funções de legislar, fiscalizar o Poder Executivo e representar o povo, os Estados e o Distrito Federal.

A primeira dessas funções - legislativa - está expressa na Constituição Federal de 1988, arts. 48, 51 e 52, nos dispositivos que regem os assuntos sobre os quais cabe ao Congresso Nacional, à Câmara dos Deputados e ao Senado Federal dispor (legislar).

A segunda função - fiscalizatória -, presente no art. 49, X, prevê que é da competência exclusiva do Congresso Nacional "fiscalizar e controlar, diretamente, ou por qualquer de suas Casas, os atos do Poder Executivo, incluídos os da administração indireta".

A terceira função - representativa - está prescrita nos arts. 45 e 46, que determinam, respectivamente: "A Câmara dos Deputados compõe-se de representantes do povo, eleitos, pelo sistema proporcional, em cada Estado, em cada Território e no Distrito Federal"; e "O Senado Federal compõe-se de representantes dos Estados e do Distrito Federal, eleitos segundo o princípio majoritário".

Centrando-nos no âmbito da atuação da Câmara dos Deputados, discorreremos, a seguir, sobre a função representativa, por considerarmos que ela antecede as demais, uma vez que é em nome do povo que a elegeu que a Câmara dos Deputados legisla. É, também, em nome do povo que essa Casa Legislativa fiscaliza os atos do Poder Executivo. Assim, a forma como a função representativa é desempenhada afeta a qualidade da atuação legislativa e fiscalizatória.

Idealmente, espera-se que o corpo de deputados federais eleitos desempenhe seu mandato em nome do povo. Isso envolve muitos aspectos, desde o conceito e abrangência da 
representação, os anseios e necessidades da sociedade, até a consciência do cidadão a respeito da titularidade do poder.

Quando se trata da representação do povo pelo parlamentar, é preciso refletir, de um lado, sobre o entendimento que o representante tem em relação ao público que representa. Será que o deputado federal considera como seus mandatários exclusivamente as categorias específicas que o elegeram, às quais prometeu apoio durante a campanha eleitoral? Ou ele se percebe como representante de todos os eleitores que nele votaram? Ou, mais ainda, será que o parlamentar compreende-se representante da população abrangida pela atuação da Câmara dos Deputados, o que equivaleria a toda a população brasileira?

De outro lado, também é importante buscar conhecer a perspectiva da população, que é a titular do poder exercido pelo Legislativo. $\mathrm{O}$ eleitor reconhece como seu representante apenas aquele parlamentar em quem votou, ou estende essa representação a todo o colegiado eleito?

As respostas a esses questionamentos são fundamentais para a compreensão do funcionamento do Legislativo. É preciso entender a qualidade da representação vigente na Câmara dos Deputados, para que seja possível promover ações que visem a melhorar a relação estabelecida entre o Legislativo e a sociedade, atualmente pautada pela desconfiança e pela péssima imagem das casas legislativas em geral.

Outro aspecto merecedor de reflexão é a contraposição entre os anseios e as necessidades da sociedade. Aquilo que a sociedade expressa como seus desejos, como expectativas, corresponde ao que ela verdadeiramente necessita? Ou serão manifestados anseios individuais, classistas, segmentados? Terá a própria sociedade consciência das suas necessidades? Mais ainda: o povo tem consciência da real dimensão do poder do qual é titular? Saberá o povo, ao menos, que é o titular desse poder?

$\mathrm{O}$ entrelaçamento de todos esses elementos tece o pano de fundo da democracia participativa brasileira. Que público é representado? Que público influencia ou participa das decisões? Que interesses são priorizados pelo parlamentar no exercício de seu mandato?

O povo brasileiro é, em sua maioria, composto por pessoas de pouca escolaridade, vivendo em contexto de baixa renda, apartadas dos fóruns de discussão e desamparadas pelas instituições governamentais que deveriam lhes garantir, no mínimo, educação, saúde e segurança.

Paradoxalmente, trata-se de um povo acostumado a receber ajuda do Estado (no sentido assistencialista), que oferece aos desfavorecidos suas múltiplas "bolsas-auxílio", prática que corrompe a iniciativa e a força laboral do cidadão. O povo brasileiro é doutrinado pelo Estado para ser passivo, acomodado, obediente e subserviente.

Desse estado de torpor resulta a eleição de um conjunto de parlamentares malescolhidos. Em uma relação contaminada pelas práticas patrimonialistas, os votos dos eleitores são negociados em troca de benefícios, que vão desde cestas básicas até cargos no governo. 
Então, configura-se um parlamento que, aos olhos da sociedade, não lhe representa. E também não the espelha. Dessa percepção, cresce a cisão entre o parlamento e a sociedade, o que é uma ameaça para a democracia participativa, na medida que desmotiva a participação popular.

Diante desse contexto, o que a Câmara dos Deputados pode fazer para aprimorar a sua função representativa? Partimos do pressuposto de que a representação é uma via de mão dupla, que depende das características tanto do representante quanto do representado, salientando-se, no entanto, que a qualidade do mandatário do poder é consequência da qualidade daquele que lhe delega esse poder, visto que é o eleitor que, por meio do voto, escolhe seu representante.

Em razão dessa lógica e com vistas a fortalecer a função representativa da Câmara dos Deputados, percebemos como prioritárias ações voltadas para a educação da sociedade. Além da incumbência de fiscalizar a implementação das políticas pelo Executivo, o Legislativo tem, ele próprio, o dever de propor e aprimorar essas políticas.

No contexto atual, recomendamos a iniciativa de políticas públicas dirigidas à educação cidadã. Nas últimas décadas, disciplinas como Educação Moral e Cívica e Organização do Estado Brasileiro foram praticamente erradicadas dos currículos do Ensino Fundamental, Médio e Superior. Não há mais, na vida escolar, educação para a cidadania. O indivíduo cresce sem a noção de pertencimento a um Estado, sem apropriar-se dos seus direitos e sem a consciência de seus deveres para com a coletividade.

A formação do cidadão, por meio de atividades que lhe transmitam informação e favoreçam a reflexão sobre conteúdos pertinentes à cidadania será, certamente, uma medida eficaz para despertar-lhe a consciência e incentivar sua participação nos assuntos do Estado, que são, em primeira e em última instância, assuntos de seu interesse, pois toda ação do Estado repercute na vida do cidadão.

A educação é a maior riqueza que se pode oferecer ao povo de qualquer Nação. A educação é libertadora, pois informa, instrui e conduz à reflexão, bases para o conhecimento. E o conhecimento, por sua vez, é a base para boas escolhas. A ignorância é o pior dos algozes, pois aprisiona, por entorpecer o sujeito e lhe tirar o discernimento. A ignorância pode ser comparada, também, à cegueira.

Assim, a priorização da educação do povo brasileiro, combinando iniciativas voltadas para o aumento da escolaridade média nacional com ações focadas na educação para a cidadania, apresentará impacto significativo na qualidade da participação popular. Mudanças nessa qualidade da participação, por sua vez, produzirão efeito na qualidade da representação, o que refletirá, finalmente, na qualidade da democracia.

\section{Referências}

AMES, José Luiz. Democracia e representação. Disponível em: <http://www.orecado.org/2006/08/democracia-e-representacao/>. Acesso em: $1^{\circ}$ out. 2010. 
BENEVIDES, M. V. M. A cidadania ativa: referendo, plebiscito e iniciativa popular. São Paulo: Ática, 2002.

BRESSER-PEREIRA, L. C. Democracia republicana e participativa. Novos Estudos Cebrap, 71, março 2005, p. 77-91.

BRESSER-PEREIRA, L. C. Democracia, Estado social e reforma Gerencial. RAE. São Paulo, v. 50, n.1, jan./mar. 2010, p. 112-116.

CÂMARA DOS DEPUTADOS. PT supera PMDB e passa a ter maior bancada da Câmara. Disponível em: <http://www2.camara.gov.br/a-camara/conheca/camara-destaca/a-camaraeleicoes>. Acesso em 7 out. 2010.

CÂMARA DOS DEPUTADOS. Veja infográfico com balanço das eleições para deputado. Disponível em: <http://www2.camara.gov.br/agencia/noticias/POLITICA/150677INFOGRAFICO:-O-BALANCO-DAS-ELEICOES-PARA-DEPUTADOFEDERAL.htm>. Acesso em 7 out. 2010.

CAMPOS, Marcelo da Silveira. Mídia e Política: a construção da agenda nas propostas de redução da maioridade penal na Câmara dos Deputados. Opinião Pública v. 15, n. 2, Campinas, nov. 2009. Disponível em: <http://www.scielo.br/scielo.php?pid=S010462762009000200008\&script=sci_arttext $>$. Acesso em: 29 set. 2010.

CARVAlHO, J. M. Cidadania no Brasil: o longo caminho. Rio de Janeiro: Civilização Brasileira, 2008. Disponível em: <http://books.google.com.br/books?hl=ptBR\&lr=\&id=Bu5TG8yI_1oC\&oi=fnd\&pg=PA7\&dq=cidadania\&ots=gOKSe5itIK\&sig=4CCY MkUowrOcdXvFHtO2wPXENzs\#v=onepage\&q\&f=false>. Acesso em: 20 ago. 2010.

COUTINHO, M. J. V. Administração pública voltada para o cidadão: quadro teórico-conceitual. Revista do Serviço Público, Ano 51, N. 3, Jul.-Set. 2000.

CHAUÍ, M. S. Cultura e democracia: o discurso competente e outras falas. São Paulo: Cortez, 2001.

DATAFOLHA. Reprovação ao Congresso Nacional passa de $39 \%$ para 33\%. São Paulo, mar.2010. Disponível em:

<http://datafolha.folha.uol.com.br/po/ver_po.php?session=956>. Acesso em 3 out. 2010.

DIAP. Eleições 2010: veja como fica a composição do Senado a partir de 2011. Disponível em: <http://www.diap.org.br/index.php/noticias/agencia-diap/14587-eleicoes-2010-veja-comofica-a-composicao-do-senado-a-partir-de-2011>. Acesso em 7 out. 2010.

HOWLETT, M. A dialética da Opinião Pública: efeitos recíprocos da política pública e da opinião pública em sociedades democráticas contemporâneas. Opinião Pública, Campinas, v. 6, $\mathrm{n}^{\mathrm{o}} 2$ 2, 2000. Disponível em: <http://www.scielo.br/scielo.php?script=sci_arttext\&pid=S0104$62762000000200001>$. Acesso em 29 set. 2010

MOISÉS, José Álvaro. Cultura política, instituições e democracia: lições da experiência brasileira. Rev. Bras. Ci. Soc. v. 23 n. 66 São Paulo Feb. 2008. Disponível em: <http://www.scielo.br/scielo.php?pid=S0102-

$69092008000100002 \&$ script=sci_arttext $>$. Acesso em $1^{\circ}$ out. 2010

VIEIRA, L. Os argonautas da cidadania: a sociedade civil na globalização. Rio de Janeiro: Record, 2001. Disponível em: <http://books.google.com.br/books?hl=pt- 
BR\&lr=\&id=5pIfbj3QcZMC\&oi=fnd\&pg=PA15\&dq=cidadania\&ots=byZKKRrGAe $\&$ sig $=$ SIc 6SquFNAPrrSser-7aR8FfURg\#v=onepage \&q\&f=false>. Acessado em 20 ago. 2010.

Artigo recebido em: 13/12/2010

Artigo aceito para publicação em: 09/03/2011 